\title{
The Roles of Mitogen-Activated Protein Kinase Pathways in TGF- $\beta$-Induced Epithelial-Mesenchymal Transition
}

\author{
Ting Gui, Yujing Sun, Aiko Shimokado, and Yasuteru Muragaki \\ First Department of Pathology, Wakayama Medical University School of Medicine, 811-1 Kimiidera, Wakayama 641-0012, Japan \\ Correspondence should be addressed to Yasuteru Muragaki,ymuragak@wakayama-med.ac.jp
}

Received 15 August 2011; Revised 22 October 2011; Accepted 23 October 2011

Academic Editor: Karl Matter

Copyright (C) 2012 Ting Gui et al. This is an open access article distributed under the Creative Commons Attribution License, which permits unrestricted use, distribution, and reproduction in any medium, provided the original work is properly cited.

\begin{abstract}
The mitogen-activated protein kinase (MAPK) pathway allows cells to interpret external signals and respond appropriately, especially during the epithelial-mesenchymal transition (EMT). EMT is an important process during embryonic development, fibrosis, and tumor progression in which epithelial cells acquire mesenchymal, fibroblast-like properties and show reduced intercellular adhesion and increased motility. TGF- $\beta$ signaling is the first pathway to be described as an inducer of EMT, and its relationship with the Smad family is already well characterized. Studies of four members of the MAPK family in different biological systems have shown that the MAPK and TGF- $\beta$ signaling pathways interact with each other and have a synergistic effect on the secretion of additional growth factors and cytokines that in turn promote EMT. In this paper, we present background on the regulation and function of MAPKs and their cascades, highlight the mechanisms of MAPK crosstalk with TGF- $\beta$ signaling, and discuss the roles of MAPKs in EMT.
\end{abstract}

\section{Introduction}

Signal transduction networks allow cells to perceive changes in the intra- and extracellular environment and respond to them appropriately. Mitogen-activated protein kinase (MAPK) cascades are one of the most thoroughly studied signal transduction systems and have been shown to participate in a diverse array of cellular programs, including cell differentiation, movement, division, and death [1]. MAPKs are serine/threonine kinases that play important roles in a vast array of pathophysiological processes. The family is divided into four main subfamilies: extracellular-regulated kinases (ERKs), Jun N-terminal kinases (JNKs), p38 MAPK, and ERK5. All of these proteins are characterized by the presence of a typical activation module and a conserved activation domain [2]. ERK1 and ERK2 are activated by mitogenic stimuli, whereas JNK and p38 MAPK, which are also called stressactivated protein kinases (SAPKs), are activated by environmental and genotoxic stresses [3-5]. The ERK5 cascade is a MAPK pathway that transmits both mitogenic and stress signals, yet its mechanism of activation is not fully understood [6]. MAPK can be regulated by TGF- $\beta$ stimulation [7], which represents an important mechanism for Smad-independent
TGF- $\beta$ signaling. Here, we focus mainly on the cross-talk between MAPK and TGF- $\beta$ signaling.

The TGF- $\beta$ superfamily of signaling molecules controls a diverse set of cellular responses, including cell proliferation, differentiation, extracellular matrix remodeling, and embryonic development. Consequently, when not strictly controlled, TGF- $\beta$ signaling can contribute to the pathogenesis of cancer as well as fibrotic, cardiovascular, and autoimmune diseases $[8,9]$. Members of the TGF- $\beta$ superfamily (e.g., TGF- $\beta$ s, activins, and bone morphogenetic proteins (BMPs)) signal via heteromeric serine/threonine kinase transmembrane receptor complexes [10-13]. The effects of TGF- $\beta$ are mediated by three TGF- $\beta$ ligands, TGF- $\beta 1,2$, and 3 via TGF- $\beta$ type I and II receptors $[9,14,15]$. The binding of the ligand to its primary (type II) receptor, a constitutively active kinase, allows the recruitment, trans-phosphorylation, and activation of the signaling (type I) receptor. The receptor, also known as activin receptor-like kinase 5 (ALK5), is then able to exert its phosphorylation-dependent serine-threonine kinase activity to phosphorylate Smad 2 and Smad3 [16-18]. These receptor-activated Smads (R-Smads) interact directly with and are phosphorylated by activated TGF- $\beta$ receptor type I $[19,20]$. Smad1, Smad5, and Smad8 
are specific substrates of the BMP receptors, whereas Smad2 and Smad 3 are activated by both TGF- $\beta$ and activin receptors $[17,21]$. Upon phosphorylation, they form heteromeric complexes with Smad4 [22], a common mediator of all Smad pathways. The resulting Smad heterocomplexes are then translocated into the nucleus where they activate target genes by either binding DNA directly or in association with other transcription factors $[10,12,13,17,18]$. Members of the third group of Smads, known as inhibitory Smads (Smad6 and Smad7) [23], control Smad signaling by preventing the phosphorylation and/or nuclear translocation of receptorassociated Smads and by inducing receptor complex degradation through the recruitment of ubiquitin ligases [24-26]. More recently, Smad7 was shown to recruit the protein phosphatase complex, type 1 protein serine/threonine phosphatase (PP1), and growth arrest and DNA damage-inducible protein 34 (GADD34) to activated TGF- $\beta$ receptors, stabilizing them and thereby inducing receptor dephosphorylation and deactivation [26]. Following target gene transcription, Smad complexes are released from the chromatin and may undergo ubiquitination and subsequent proteasomal degradation.

These Smad pathways are not the only means by which TGF- $\beta$ s regulate cellular functions. Smad-independent pathways including the mitogen-activated protein kinase (MAPK), nuclear factor $\kappa$-light chain-enhancer of activated B cells $(\mathrm{NF}-\kappa \mathrm{B})$, and PI3 kinase/AKT pathways also participate in TGF- $\beta$ signaling, and these pathways can either be induced by TGF- $\beta$ or modulate the outcome of TGF- $\beta$-induced Smad signaling $[21,27,28]$. Indeed, broad evidence suggests that Smad signaling is tightly integrated within a complex network of signaling pathways with cross-talk that modify the initial Smad signals and allow the pleiotropic activities of TGF- $\beta$. There are also instances in which Smad signaling is not required for some TGF- $\beta$ responses, as exemplified by the Smad-independent activation of the cyclin kinase inhibitors p15 and p21 in HaCaT keratinocytes, and the transcriptional activation of the fibronectin promoter via MAPK-dependent mechanisms. It appears clear that Smad proteins are not only the primary substrates for the TGF- $\beta$ receptor kinases but may also be phosphorylated by MAPKs in response to either TGF- $\beta$ itself or to various cytokines. Such R-Smad phosphorylation by MAPKs may serve to regulate Smad by modulating either its transcriptional activity or its capacity to translocate into the cell nucleus $[28,29]$. Smad proteins are also capable of physically interacting with transcription factors that are also substrates of MAPKs, adding more complexity to the already intricate relationship between the MAPK and Smad pathways.

The epithelial-mesenchymal transition (EMT) is a complex, stepwise phenomenon that occurs during embryonic development and tumor progression [30]. EMT is also associated with chronic inflammatory and fibrogenic diseases that affect the lungs, the liver, and the peritoneum of patients undergoing peritoneal dialysis $[31,32]$. EMT and the reverse process, termed the mesenchymal-epithelial transition (MET), play central roles in embryogenesis, cancer invasion and metastasis, and fibrosis [33, 34]. EMT is characterized by the disruption of intercellular junctions, the replacement of apical-basolateral polarity with front-toback polarity, and the acquisition of migratory and invasive phenotypes. Cells that have undergone EMT also acquire the capacity to produce extracellular matrix (ECM) components and a wide spectrum of inflammatory, fibrogenic, and angiogenic factors [35]. EMT is triggered by the interplay of several extracellular signals, such as ECM components, soluble growth factors, and cytokines. These signals include members of the TGF- $\beta$ and fibroblast growth factor families, epidermal growth factor, and hepatocyte growth factor [30]. TGF- $\beta$ was first described as an inducer of EMT in normal mammary epithelial cells, and several studies have established crucial roles for TGF- $\beta$-induced EMT [36].

A key question in studies of MAPK is how a ubiquitously active regulatory enzyme generates a specific and biologically appropriate cellular response during EMT. This paper will summarize some of the latest data from the literature regarding the interactions among MAPK, TGF- $\beta$, and other factors, with a major focus on the cellular events that contribute to EMT.

\section{Four Subfamilies of MAP Kinases and Their Substrates in Each Signaling Cascade}

MAP kinases are a large group of proteins that allow numerous extracellular signals to rapidly activate nuclear transcription factors [37] (Figure 1). They consist of at least four subfamilies: the extracellular signal-regulated kinases (ERK1 and ERK2), the stress-activated protein (SAP) kinases, known as c-Jun $\mathrm{N}$-terminal kinases (JNK1, JNK2, and JNK3), the p38 MAPKs $(\alpha, \beta, \gamma$, and $\delta)$ [2], and ERK5 [38]. ERK5, which is also known as big MAP kinase 1 (BMK1) and has been described as a mediator of Src activation [39], is twice as large as other MAPKs [40].

Signaling initiated by each MAPK pathway occurs through the sequential phosphorylation of a MAPK kinase kinase (MAPKKK), a MAPK kinase (MAPKK), and a MAPK by membrane-associated kinases, such as cytokine or growth factor receptors [41]. MAPK activation leads to the downstream phosphorylation of nuclear kinases or, most commonly, transcription factors. Figure 1 provides a simplified view of the various MAPK pathways and includes most of the MAPK members and substrates cited in the text below.

ERK1 and ERK2, isoforms of the classical MAPK, are phosphorylated by the MAPKKs MEK1 (for MAPK/ERK kinase 1) and MEK2, which are substrates of the MAPKKK Mos and Raf-1 [42]. Raf-1 is activated by the membranebound small G-protein Ras following induction by mitogenic stimuli, such as epidermal growth factor (EGF), upon binding and activation of their respective receptors (i.e., EFGR). ERK-mediated pathways are mainly involved in proliferation and differentiation and are generally considered antiapoptotic.

JNK family members are the substrates of MAPK kinase 4 (MKK4, also known as SEK1) and MKK7. p38 MAPK is phosphorylated by MKK3 and MKK6, which are the substrates of apoptosis signal-regulating kinase-1 (ASK1), mixed lineage kinases (MLK), and TGF- $\beta$-activated kinase- 1 


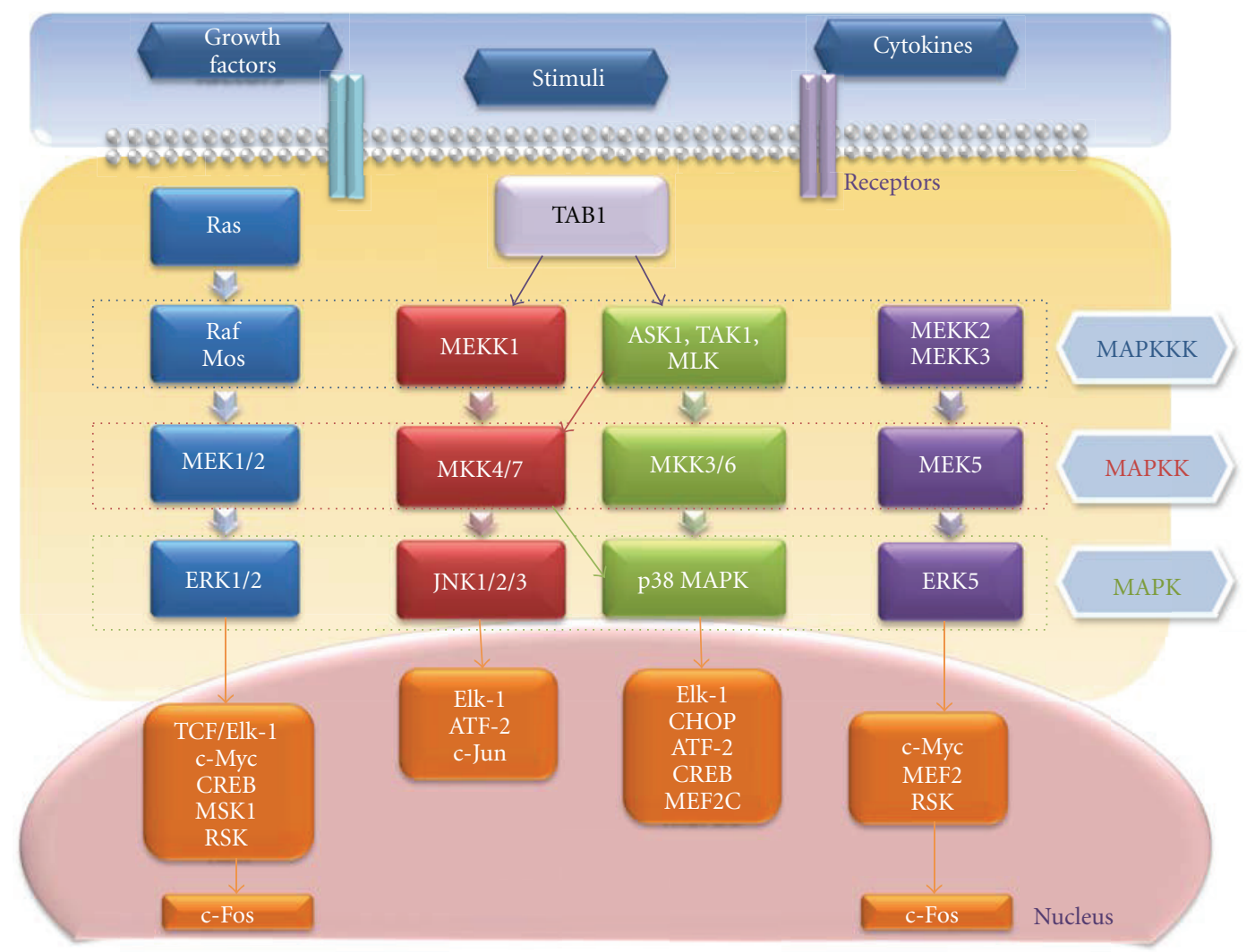

FIgURE 1: The network of the mitogen-activated protein kinase (MAPK) family. Extracellular stimuli transduce signals to the nucleus. The sequential phosphorylation of MAPKKK, MAPKK, and MAPK activates their nuclear targets, kinases, and transcription factors. For details, refer to the text.

(TAK1) $[43,44]$. MEK kinase (MEKK1) and TAK1 activate JNK through MKK4 or MKK7 and activate p38 MAPK through MKK3 or MKK6. JNK and p38-signaling pathways are activated by stress stimuli, many of which induce apoptosis, but, in some cellular systems, they have also been implicated in proliferation and differentiation $[45,46]$.

Upon ERK5 stimulation, two members of the MAPKKK family, MEKK2 and MEKK3, activate MEK5, a MAPKK that is specific for ERK5 [47]. Unlike the first three groups of MAPKs, this pathway has not yet been clearly shown to be activated by TGF- $\beta$ or to interfere with Smad signaling.

MAPK pathways control the cell response to changes in the extracellular environment through the regulation of transcription factors in the nucleus [48]. Thus, to transmit extracellular signals to the nucleus, the terminal components of the MAPK pathways, such as ERK1/2, JNK, and p38 MAPK, must translocate to the nucleus.

A variety of transcription factors and downstream kinases serve as substrates for activated MAPKs [49, 50]. These include activating protein-1 (AP-1), a family of pleiotropic transcription factors comprised of homo- and heterodimers of Fos, Jun, and activating transcription factor (ATF) family members that are involved in the control of cell proliferation, death, and survival, as well as tumorigenesis [51, 52]. Activated ERK1/2 phosphorylates many substrates, including TCF/Elk-1 and c-Myc, and activates cAMP response element binding protein (CREB) and protein kinases, such as mitogen- and stress-activated protein kinase 1 (MSK1) and ribosomal S6 kinase (RSK), which subsequently induces the immediate early gene c-Fos $[53,54]$.

p38 MAPKs activate many substrates including E twenty six-like transcription factor 1 (Elk-1), CCAAT/enhancer binding protein homologous protein (CHOP), ATF-2, CREB, and myocyte-specific enhancer factor 2C (MEF2C) [55]. JNK is the only MAPK that phosphorylates c-Jun, the main component of AP-1 complexes, and also acts on ATF-2 and Elk-1 $[2,56]$. Phosphorylation of c-Jun activates this key member of the AP- 1 family of transcription factors, which can then bind the specific AP-1 recognition sites TGAG/CTCA to transactivate target genes [57]. Upon activation, CREB and ATF-2 bind to CRE sites (TGACGTCA) within target gene promoters [58]. Heterodimers of c-Jun and ATF-2 have also been shown to bind to CRE sites [59]. ERK5, similar to ERK1/2, phosphorylates c-Myc, MEF2, and RSK, subsequently inducing c-Fos $[60,61]$.

\section{Smad-Dependent and -Independent MAPK Activation by TGF- $\beta$}

TGF- $\beta$ has been shown to activate all ERK, p38 MAPK, and JNK MAPKs in numerous cell types [62-65] through Smaddependent and -independent transcriptional mechanisms. 
Because MAPK activation is not a specific feature of TGF$\beta$ signaling and may be produced by various extracellular stimuli, including cytokines, ultraviolet irradiation, cell-cell or cell-matrix contacts [66-68], the outcome of Smad-dependent or -independent MAPK interactions should be viewed not only as the result of TGF- $\beta$ signaling but also as a consequence of cytokine networks acting in concert to modulate MAPK signals.

As an example of Smad-dependent MAPK activation, in mink lung epithelial cells, TGF- $\beta$-induced activation of JNK mediates Smad3 phosphorylation, which is required for Smad3-dependent transcriptional responses [69] (Figure 2).

However, the initial evidence for Smad-independent activation of MAPK by TGF- $\beta$ came from the observation that the activation of JNK in response to the TGF- $\beta$ pathway was possible in Smad4-deficient cells and cells overexpressing dominant-negative Smads, despite the deficient Smad cascade. It has also been shown that a mutated TGF- $\beta$ type I receptor that cannot phosphorylate R-Smad can still activate p38 MAPK signaling in response to TGF- $\beta[70,71]$.

Several other Smad-independent signaling examples have been described in the literature. TGF- $\beta$ can activate ERK via rapid activation of Ras in rat intestine [72] (Figure 3). TGF- $\beta$ type I receptor could phosphorylate the ShcA adaptor protein that subsequently associates with Grb2 and Sos in the cytoplasm in the absence of ligand stimulation [73, 74] (Figure 3). The ShcA/Grb/Sos complex is a well-established link between receptor tyrosine kinases and the MEK and ERK pathway via Ras and Raf activation [75].

The mechanisms of ERK, JNK, or p38 MAPK activation by TGF- $\beta$ and the associated biological consequences are not fully characterized. ERK activation by TGF- $\beta$ in epithelial cells may involve Ras signaling [76], while JNK and p38 MAPK signaling could be activated by various MAPKKKs in response to various stimuli. The first MAPKKK known to be activated by TGF- $\beta$ family members was TGF- $\beta$-activated kinase 1 (TAK1), which was originally identified as a MAPKKK activated by TAB1 (TGF- $\beta$-activated kinase-binding protein-1) downstream of TGF- $\beta /$ BMP receptors. TAK1 positively regulates the JNK and p38 kinase pathways [77] (Figure 2).

TGF- $\beta 1$ may induce rapid and prolonged activation of p38 MAPK, depending on the cell type. Rapid and transient p38 MAPK activation has been described in certain cell types, including human neutrophils, HEK293, and C2C12 cells, and may be mediated by the induction of TAK1 in an RSmad-independent manner. On the other hand, the prolonged and sustained p38 MAPK activation observed in pancreatic carcinoma cells, hepatocytes, and osteoblasts requires Smad signaling. Smad activation induces the expression of GADD $45 \beta$, an upstream activator of MKK4, and thus promotes the prolonged activation of p38 MAPK [78] (Figure 2). Functional differences between rapid and prolonged activation of p38 MAPK may be dependent on cell type, but, at least in pancreatic cells, prolonged activation through the Smad-mediated induction of GADD $45 \beta$ may contribute to the tumor-suppressive effect of TGF- $\beta$ [78].

\section{The Association between MAPK and TGF- $\beta$ Signaling in EMT}

EMT is a complex process involving a restructuring of the cytoskeleton, cell membrane, and cell-cell junctions. Previous studies have implicated several molecules in different aspects of EMT. However, the aspects of EMT that might be mediated by MAPK signaling have not yet been defined.

ERK activation may be important for several key features of EMT that could cause the loss of epithelial characteristics and acquisition of mesenchymal properties, including the downregulation of adherens junctions and their affiliated proteins (e.g., E-cadherin), increased MMP activity, the induction of actin stress fibers, and the acquisition of motile and invasive properties [79-81]. ERK activation is one of the Smad-independent events that is necessary for TGF- $\beta$-mediated EMT $[82,83]$. ERK is required for the disassembly of cell adherens junctions and the induction of cell motility by TGF- $\beta$. In a transcriptomic screen of genetic programs for TGF- $\beta$-induced EMT, TGF- $\beta$-stimulated ERK activation regulates a subset of target genes, a large proportion of which have defined roles in cell-matrix interactions, cell motility, and endocytosis [82]. These genes are known to function in the remodeling of integrin-based cell-matrix adhesion and in promoting cell motility.

The loss of E-cadherin is a critical step in EMT [84]. There is compelling evidence that ERKs repress E-cadherin expression to drive EMT in many experimental systems [85]. Previous studies have demonstrated that ERK is rapidly activated by TGF- $\beta$ in culture models of EMT, and a specific inhibitor of MEK (upstream of ERK) blocks key morphologic features of EMT, such as the disassembly of E-cadherin-mediated adherens junctions, in various models [86, 87]. Several transcriptional repressors of E-cadherin have now been identified, including two members of the Snail superfamily of the zinc-finger transcription factors, Snail [88] and Slug [89]. Choi et al. found that TGF- $\beta 1$-induced Slug expression was significantly inhibited by MEK- and JNK-specific inhibitors, indicating that MAPK pathways are involved in the regulation of Slug expression by TGF- $\beta 1$ [90].

Recent data suggest that the aberrant activation of ERK may play an important role in diverting the TGF- $\beta$ response towards EMT in kidney epithelial cells. Raf activation confers protection against TGF- $\beta$-induced apoptosis while enhancing the proinvasive effects of TGF- $\beta$ [91]. Furthermore, the induction of EMT in breast tumor cells is dependent on the presence of both activated Ras and a functional TGF- $\beta$ autocrine loop that is enhanced by $\operatorname{Ras}[86,91]$. Gene array data obtained from human keratinocytes induced to undergo EMT by TGF- $\beta$ provided the first insights into ERK-dependent gene targets with roles in cell-matrix interactions and cell motility [92].

Perhaps the best-characterized interaction between TGF$\beta$ and MAPK signaling involves the JNK and p38 MAPK signaling cascades (Figure 2 ). TGF- $\beta$ can rapidly activate JNK through MKK4 $[69,93]$ and p38 MAPK through MKK3/6 in various cell lines $[70,94]$. Further upstream, MKKs are activated by the MAPKKKs; TAK1 is one of these activating MAPKKKs. Because TAK1 is rapidly induced by TGF- $\beta 1$ and 


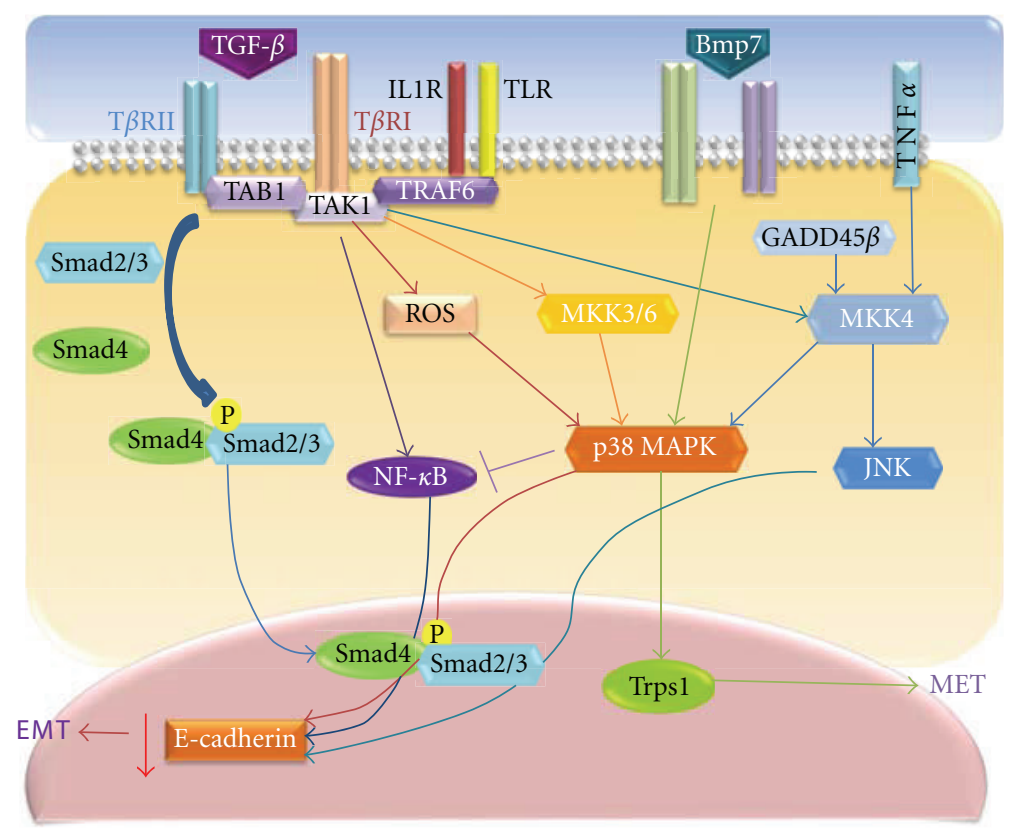

FIGURE 2: The involvement of JNK and p38 MAPK pathways in the TGF- $\beta$-induced epithelial-mesenchymal transition. Upon TGF- $\beta$ ligation, the receptor phosphorylates Smad2/3 and interacts with TRAF6, which recruits TAK1 and TAB1 to activate JNK and p38 MAPK. The activated JNK and p38 MAPK can act in a Smad-dependent or -independent manner to regulate EMT by controlling the downstream transcriptional factors. This figure depicts the cross-talk between JNK, p38 MAPK, and TGF- $\beta$ signaling in different cellular systems and illustrates how these networks may function in a stimuli-dependent manner to determine the EMT response.

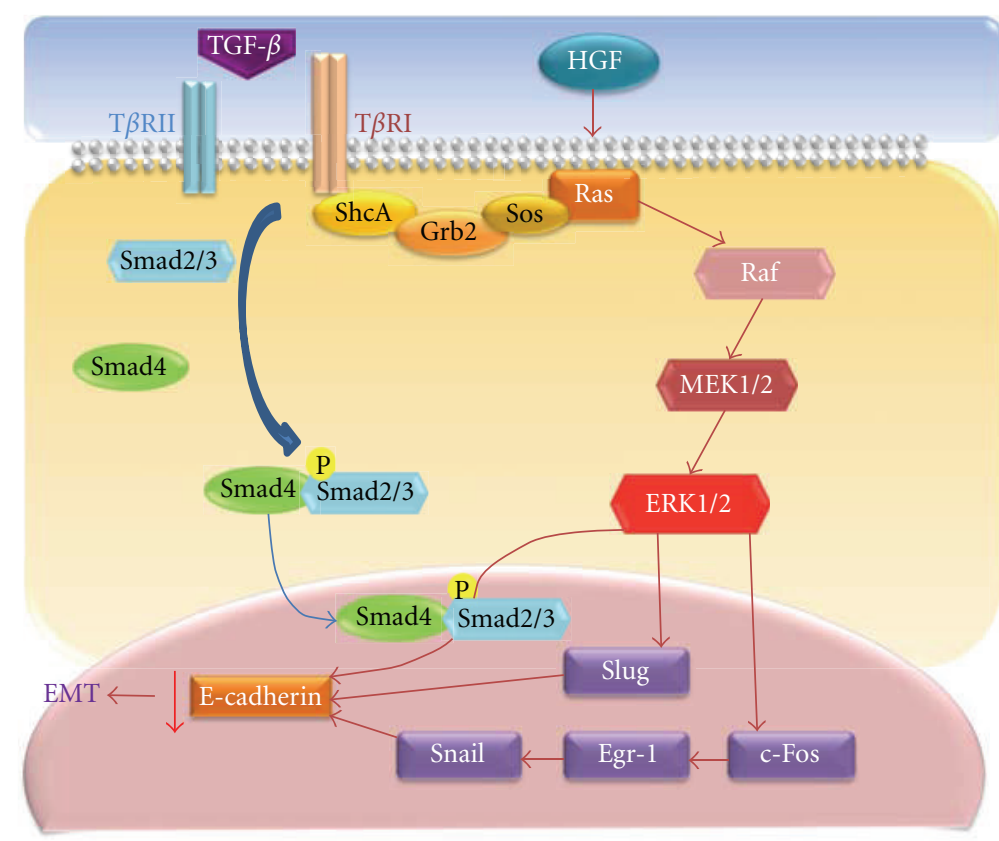

FIGURE 3: The involvement of the ERK pathway in the TGF- $\beta$-induced epithelial-mesenchymal transition. After TGF- $\beta$ induces the phosphorylation of serine and/or tyrosine on T $\beta$ RI and/or ShcA, ShcA is capable of recruiting Grb2 and Sos to active ERK1/2 through Ras, Raf, and MEK1/2. The activation of Ras can also be induced by HGF to control the EMT, which is regulated by Snail. This figure depicts the cross-talk between ERK, TGF- $\beta$, and other factors in different cellular systems and illustrates how these networks may function in a stimuli-dependent manner to determine the EMT response. 
plays a role in p38 MAPK activation and JNK and NF- $\kappa$ B signaling [95], some researchers have focused on TAK1 and found that p38 MAPK maintains E-cadherin expression by suppressing TAK1/NF- $\kappa \mathrm{B}$ signaling, thus impeding the induction of EMT in human primary mesothelial cells [96].

TNF receptor associated factor 6 (TRAF6), which plays an important role in the activation of TAK1 in interleukin-1 receptor (IL-1R) and Toll-like-receptor-(TLR-) mediated signaling pathways, was found to be crucial for the TGF- $\beta$-induced activation of the TAK1-JNK/p38 MAPK pathways [97, 98]. The TRAF6-TAK1-JNK/p38 MAPK pathway plays an important role in TGF- $\beta$-induced EMT (Figure 2). Inhibiting p38 activity using a p38 inhibitor or dominant-negative forms of MKK3 or p38 impairs TGF- $\beta$-mediated reorganization of the actin cytoskeleton and results in changes in cell shape [99]. Knocking down TRAF6 expression also inhibits TGF- $\beta$-mediated EMT [98]. Thus, activation of the TRAF6TAK1-p38 MAPK pathway is another requirement for TGF$\beta$-induced EMT.

Studies of the roles of MAPK family proteins in the genesis of EMT have produced conflicting results, likely due to the heterogeneity of the models and the different experimental approaches used. p38 MAPK appears to promote EMT during development and in tumors $[100,101]$. According to an earlier study, p38 MAPK can regulate actin organization via heat shock protein 27 (HSP27) [102]. Therefore, p38 MAPK may function in the TGF- $\beta$-induced reorganization of the actin cytoskeleton parallel to or upstream of the RhoA/Rock pathway [103]. In addition, p38 MAPK may contribute to the expression of TGF- $\beta$ target genes that are casually involved in EMT because p38 MAPK has been implicated in TGF- $\beta$ transcriptional responses through its activation of ATF2 and Sp1 [104]. Taken together, these results suggest that the MAPK pathway contributes to TGF- $\beta$-induced changes in the actin cytoskeleton and in cell shape during EMT.

In recent years, significant evidence has indicated that the p38 MAPK pathway is an important intracellular signal transduction pathway in TGF- $\beta 1$-induced EMT in renal tubular epithelial cells $[105,106]$. Activated p38 MAPK can directly regulate the protein synthesis of $\alpha$-smooth muscle cell actin ( $\alpha$-SMA) and thus indirectly activate the Smad pathway, leading to excessive matrix deposition and finally inducing fibrosis. For example, reactive oxygen species (ROS), which have been shown to mediate TGF- $\beta$-induced cellular responses in various cells [107], play an important role in EMT in rat proximal tubular epithelial cells, primarily through the activation of MAPK but also indirectly through ERK and subsequently through the phospho-Smad2 pathway [108] (Figure 2).

Semaphorin-4C (Sema4C) is essential for the activation of p38 MAPK [109]. The semaphorins are a large family of secreted or membrane-bound proteins that share a conserved Sema domain, which is known to regulate tumor progression [110], angiogenesis [111], nervous system development [112], and immune cell interactions [113]. Sema4C plays an important role in TGF- $\beta 1$-induced EMT through its activation of p38 MAPK in proximal tubular epithelial cells [114]. Sema4C knockdown strongly inhibits the phosphorylation of p38 and reverses TGF- $\beta 1$-induced EMT. Trps1, an atypical member of the GATA-type family of transcription factors [115], acts downstream of bone morphogenetic protein 7 (BMP7) via p38 [116]. Knockdown of Trps1 or p38 MAPK inhibits the BMP7-induced MET.

In advanced stages of tumor development, TGF- $\beta$ promotes tumor metastasis by stimulating EMT, matrix metalloproteinase (MMP) expression, and by angiogenesis and inhibiting immune surveillance [117-119]. Numerous studies have revealed that TGF- $\beta$-induced EMT can be blocked by inhibiting MAPK activation. Synergy between TNF- $\alpha$ and TGF- $\beta$ signaling enables $\mathrm{p} 38$ MAPK activation to promote the rapid morphological conversion of colon carcinoma epithelia to dispersed cells with mesenchymal phenotypes [85, 120]. Hepatocyte growth factor/scatter factor (HGF) has several functions in the induction of epithelial cell scattering, motility, and tumor progression. One underlying mechanism that could explain this observation is that HGF upregulates Snail, a transcriptional repressor involved in EMT, through MAPK and early growth response factor-1 (Egr-1) (Figure 3).

\section{Future Perspective and Conclusions}

Within the past few years, considerable progress has been made toward understanding the signaling cascades and multiple pathways that involve MAPKs. At present, it is clear that cooperation between TGF- $\beta$-induced Smad signaling and the MAPK pathway determines the final cellular response to TGF- $\beta$, especially during EMT. It will not be surprising if more associations between the MAPK pathway and EMT are discovered in the future. The computational and mathematical modeling of biological systems has become increasingly valuable in recent years, and a wide variety of mathematical models of the MAPK pathway have led to some novel insights and predictions about how this system functions [121]. Further cross-talk research will undoubtedly rely on the development of new computational systems and will reveal novel mechanisms that contribute to TGF- $\beta$-dependent and independent MAPK signaling, advancing our understanding of how MAPK can induce a plethora of diverse biological responses, including EMT. A major goal will be to determine how the specificity in MAPK downstream signaling is achieved in different cell lines and animal models; this information could be used to seek out clinical advantages in combination therapy.

\section{References}

[1] H. J. Schaeffer and M. J. Weber, "Mitogen-activated protein kinases: specific messages from ubiquitous messengers," Molecular and Cellular Biology, vol. 19, no. 4, pp. 2435-2444, 1999.

[2] L. Chang and M. Karin, "Mammalian MAP kinase signalling cascades," Nature, vol. 410, no. 6824, pp. 37-40, 2001.

[3] E. F. Wagner and A. R. Nebreda, "Signal integration by JNK and p38 MAPK pathways in cancer development," Nature Reviews Cancer, vol. 9, no. 8, pp. 537-549, 2009.

[4] L. Bardwell and K. Shah, "Analysis of mitogen-activated protein kinase activation and interactions with regulators and substrates," Methods, vol. 40, no. 3, pp. 213-223, 2006. 
[5] S. J. Lee, T. Zhou, and E. J. Goldsmith, "Crystallization of MAP kinases," Methods, vol. 40, no. 3, pp. 224-233, 2006.

[6] Z. Yao, S. Yoon, E. Kalie, Z. Raviv, and R. Seger, "Calcium regulation of EGF-induced ERK5 activation: role of Lad1MEKK2 interaction," PLoS One, vol. 5, no. 9, Article ID e12627, pp. 1-10, 2010.

[7] X. Guo and X. F. Wang, "Signaling cross-talk between TGF$\beta /$ BMP and other pathways," Cell Research, vol. 19, no. 1, pp. 71-88, 2009.

[8] K. H. Wrighton, X. Lin, and X. H. Feng, "Phospho-control of TGF- $\beta$ superfamily signaling," Cell Research, vol. 19, no. 1, pp. 8-20, 2009.

[9] H. Ikushima and K. Miyazono, "TGF $\beta$ signalling: a complex web in cancer progression," Nature Reviews Cancer, vol. 10, no. 6, pp. 415-424, 2010.

[10] R. Derynck and X. H. Feng, “TGF- $\beta$ receptor signaling," Biochimica et Biophysica Acta, vol. 1333, no. 2, pp. F105-F150, 1997.

[11] X. H. Feng and R. Derynck, "A kinase subdomain of transforming growth factor- $\beta$ (TGF- $\beta$ ) type I receptor determines the TGF- $\beta$ intracellular signaling specificity," EMBO Journal, vol. 16, no. 13, pp. 3912-3923, 1997.

[12] D. Javelaud and A. Mauviel, "Transforming growth factorbetas: smad signaling and roles in physiopathology," Pathologie Biologie, vol. 52, no. 1, pp. 50-54, 2004.

[13] P. Ten Dijke and C. S. Hill, "New insights into TGF- $\beta$-Smad signalling," Trends in Biochemical Sciences, vol. 29, no. 5, pp. 265-273, 2004.

[14] C. H. Heldin, K. Miyazono, and P. Ten Dijke, "TGF- $\beta$ signalling from cell membrane to nucleus through SMAD proteins," Nature, vol. 390, no. 6659, pp. 465-471, 1997.

[15] X. H. Feng and R. Derynck, "Specificity and versatility in TGF- $\beta$ signaling through smads," Annual Review of Cell and Developmental Biology, vol. 21, pp. 659-693, 2005.

[16] R. Derynck, Y. Zhang, and X. H. Feng, "Smads: transcriptional activators of TGF- $\beta$ responses," Cell, vol. 95, no. 6, pp. 737-740, 1998.

[17] K. Miyazono, P. Ten Dijke, and C. H. Heldin, "TGF- $\beta$ signaling by Smad proteins," Advances in Immunology, vol. 75, pp. 115-157, 2000.

[18] Y. Shi and J. Massagué, "Mechanisms of TGF- $\beta$ signaling from cell membrane to the nucleus," Cell, vol. 113, no. 6, pp. 685-700, 2003.

[19] M. Schiller, D. Javelaud, and A. Mauviel, “TGF- $\beta$-induced SMAD signaling and gene regulation: consequences for extracellular matrix remodeling and wound healing," Journal of Dermatological Science, vol. 35, no. 2, pp. 83-92, 2004.

[20] C. M. Zimmerman and R. W. Padgett, "Transforming growth factor $\beta$ signaling mediators and modulators," Gene, vol. 249, no. 1-2, pp. 17-30, 2000.

[21] J. Massagué, S. W. Blain, and R. S. Lo, "TGF $\beta$ signaling in growth control, cancer, and heritable disorders," Cell, vol. 103, no. 2, pp. 295-309, 2000.

[22] N. A. Ali, M. J. McKay, and M. P. Molloy, "Proteomics of Smad4 regulated transforming growth factor-beta signalling in colon cancer cells," Molecular BioSystems, vol. 6, no. 11, pp. 2332-2338, 2010.

[23] A. Nakao, M. Afrakhte, A. Morén et al., "Identification of Smad7, a TGF $\beta$-inducible antagonist of TGF- $\beta$ signalling," Nature, vol. 389, no. 6651, pp. 631-635, 1997.

[24] Y. Zhang, C. Chang, D. J. Gehling, A. Hemmati-Brivanlou, and R. Derynck, "Regulation of Smad degradation and activity by Smurf2, an E3 ubiquitin ligase," Proceedings of the National Academy of Sciences of the United States of America, vol. 98, no. 3, pp. 974-979, 2001.
[25] T. Ebisawa, M. Fukuchi, G. Murakami et al., "Smurf1 interacts with transforming growth factor- $\beta$ type I receptor through Smad7 and induces receptor degradation," Journal of Biological Chemistry, vol. 276, no. 16, pp. 12477-12480, 2001.

[26] W. Shi, C. Sun, B. He et al., "GADD34-PP1c recruited by Smad7 dephosphorylates TGF $\beta$ type I receptor," Journal of Cell Biology, vol. 164, no. 2, pp. 291-300, 2004.

[27] J. Massagué, "How cells read TGF- $\beta$ signals," Nature Reviews Molecular Cell Biology, vol. 1, no. 3, pp. 169-178, 2000.

[28] R. Derynck and Y. E. Zhang, "Smad-dependent and Smadindependent pathways in TGF- $\beta$ family signalling," Nature, vol. 425, no. 6958, pp. 577-584, 2003.

[29] M. Lutz and P. Knaus, "Integration of the TGF- $\beta$ pathway into the cellular signalling network," Cellular Signalling, vol. 14, no. 12, pp. 977-988, 2002.

[30] J. P. Thiery, H. Acloque, R. Y. J. Huang, and M. A. Nieto, "Epithelial-mesenchymal transitions in development and disease," Cell, vol. 139, no. 5, pp. 871-890, 2009.

[31] L. S. Aroeira, A. Aguilera, J. A. Sánchez-Tomero et al., "Epithelial to mesenchymal transition and peritoneal membrane failure in peritoneal dialysis patients: pathologic significance and potential therapeutic interventions," Journal of the American Society of Nephrology, vol. 18, no. 7, pp. 2004-2013, 2007.

[32] R. Kalluri and R. A. Weinberg, "The basics of epithelialmesenchymal transition," Journal of Clinical Investigation, vol. 119, no. 6, pp. 1420-1428, 2009.

[33] J. M. Pérez-Pomares, A. Phelps, M. Sedmerova et al., "Experimental studies on the spatiotemporal expression of WT1 and RALDH2 in the embryonic avian heart: a model for the regulation of myocardial and valvuloseptal development by epicardially derived cells (EPDCs)," Developmental Biology, vol. 247, no. 2, pp. 307-326, 2002.

[34] J. P. Thiery and J. P. Sleeman, "Complex networks orchestrate epithelial-mesenchymal transitions," Nature Reviews Molecular Cell Biology, vol. 7, no. 2, pp. 131-142, 2006.

[35] S. Thomson, F. Petti, I. Sujka-Kwok et al., "A systems view of epithelial-mesenchymal transition signaling states," Clinical and Experimental Metastasis, vol. 28, no. 2, pp. 137-155, 2011.

[36] A. Moustakas and C. H. Heldin, "Signaling networks guiding epithelial-mesenchymal transitions during embryogenesis and cancer progression," Cancer Science, vol. 98, no. 10, pp. 1512-1520, 2007.

[37] A. J. Whitmarsh and R. J. Davis, "Signal transduction by MAP kinases: regulation by phosphorylation-dependent switches," Sciences STKE, vol. 1999, no. 1, p. PE1, 1999.

[38] X. Wang and C. Tournier, "Regulation of cellular functions by the ERK5 signalling pathway," Cellular Signalling, vol. 18, no. 6 , pp. $753-760,2006$.

[39] G. Zhou, Z. Q. Bao, and J. E. Dixon, "Components of a new human protein kinase signal transduction pathway," Journal of Biological Chemistry, vol. 270, no. 21, pp. 12665-12669, 1995.

[40] P. Rafiee, J. K. Lee, C. C. Leung, and T. A. Raffin, “TNF- $\alpha$ induces tyrosine phosphorylation of mitogen-activated protein kinase in adherent human neutrophils," Journal of Immunology, vol. 154, no. 9, pp. 4785-4792, 1995.

[41] V. L. Lowes, N. Y. Ip, and Y. H. Wong, "Integration of signals from receptor tyrosine kinases and $G$ protein-coupled receptors," NeuroSignals, vol. 11, no. 1, pp. 5-19, 2002.

[42] T. Joneson, J. A. Fulton, D. J. Volle, O. V. Chaika, D. BarSagi, and R. E. Lewis, "Kinase suppressor of Ras inhibits the activation of extracellular ligand-regulated (ERK) mitogenactivated Protein (MAP) kinase by growth factors, activated 
Ras, and Ras effectors," Journal of Biological Chemistry, vol. 273, no. 13, pp. 7743-7748, 1998.

[43] Y. T. Ip and R. J. Davis, "Signal transduction by the c-Jun N-terminal kinase (JNK) - from inflammation to development," Current Opinion in Cell Biology, vol. 10, no. 2, pp. 205-219, 1998.

[44] S. Davis, P. Vanhoutte, C. Pagès, J. Caboche, and S. Laroche, "The MAPK/ERK cascade targets both Elk-1 and cAMP response element- binding protein to control long-term potentiation-dependent gene expression in the dentate gyrus in vivo," Journal of Neuroscience, vol. 20, no. 12, pp. 4563-4572, 2000.

[45] R. Eferl and E. F. Wagner, "AP-1: a double-edged sword in tumorigenesis," Nature Reviews Cancer, vol. 3, no. 11, pp. 859-868, 2003.

[46] R. Zenz, H. Scheuch, P. Martin et al., "c-Jun regulates eyelid closure and skin tumor development through EGFR signaling," Developmental Cell, vol. 4, no. 6, pp. 879-889, 2003.

[47] W. Sun, K. Kesavan, B. C. Schaefer et al., "MEKK2 associates with the adapter protein Lad/RIBP and regulates the MEK5BMK1/ERK5 pathway," Journal of Biological Chemistry, vol. 276, no. 7, pp. 5093-5100, 2001.

[48] S. Pelet, F. Rudolf, M. Nadal-Ribelles, E. De Nadal, F. Posas, and M. Peter, "Transient activation of the HOG MAPK pathway regulates bimodal gene expression," Science, vol. 332, no. 6030, pp. 732-735, 2011.

[49] R. Treisman, "Regulation of transcription by MAP kinase cascades," Current Opinion in Cell Biology, vol. 8, no. 2, pp. 205-215, 1996.

[50] D. Javelaud and A. Mauviel, "Crosstalk mechanisms between the mitogen-activated protein kinase pathways and Smad signaling downstream of TGF- $\beta$ : implications for carcinogenesis," Oncogene, vol. 24, no. 37, pp. 5742-5750, 2005.

[51] M. Karin, Z. G. Liu, and E. Zandi, "AP-1 function and regulation," Current Opinion in Cell Biology, vol. 9, no. 2, pp. 240-246, 1997.

[52] E. Shaulian and M. Karin, "AP-1 as a regulator of cell life and death," Nature Cell Biology, vol. 4, no. 5, pp. E131-E136, 2002.

[53] C. Hauge and M. Frödin, "RSK aand MSK in MAP kinase signalling," Journal of Cell Science, vol. 119, no. 15, pp. 30213023, 2006.

[54] M. D. Godeny and P. P. Sayeski, "ERK1/2 regulates ANG II-dependent cell proliferation via cytoplasmic activation of RSK2 and nuclear activation of elk1," American Journal of Physiology, vol. 291, no. 6, pp. C1308-C1317, 2006.

[55] C. A. Hazzalin and L. C. Mahadevan, "MAPK-regulated transcription: a continuously variable gene switch?" Nature Reviews Molecular Cell Biology, vol. 3, no. 1, pp. 30-40, 2002.

[56] D. Hao, P. Gao, P. Liu et al., "AC3-33, a novel secretory protein, inhibits Elk1 transcriptional activity via ERK pathway," Molecular Biology Reports, vol. 38, no. 2, pp. 1375-1378, 2011.

[57] P. Angel and M. Karin, "The role of Jun, Fos and the AP-1 complex in cell-proliferation and transformation," Biochimica et Biophysica Acta, vol. 1072, no. 2-3, pp. 129-157, 1991.

[58] T. Smeal, M. Hibi, and M. Karin, "Altering the specificity of signal transduction cascades: positive regulation of c-Jun transcriptional activity by protein kinase A," EMBO Journal, vol. 13, no. 24, pp. 6006-6010, 1994.

[59] T. Hai and T. Curran, "Cross-family dimerization of transcription factors Fos/Jun and ATF/CREB alters DNA binding specificity," Proceedings of the National Academy of Sciences of the United States of America, vol. 88, no. 9, pp. 3720-3724, 1991.
[60] S. Kamakura, T. Moriguchi, and E. Nishida, "Activation of the protein kinase ERK5/BMK1 by receptor tyrosine kinases. Identification and characterization of a signaling pathway to the nucleus," Journal of Biological Chemistry, vol. 274, no. 37, pp. 26563-26571, 1999.

[61] S. Bailey, A. G. Hall, A. D. J. Pearson, and C. P. F. Redfern, "The role of AP-1 in glucocorticoid resistance in leukaemia," Leukemia, vol. 15, no. 3, pp. 391-397, 2001.

[62] L. M. Wakefield and A. B. Roberts, "TGF- $\beta$ signaling: positive and negative effects on tumorigenesis," Current Opinion in Genetics and Development, vol. 12, no. 1, pp. 22-29, 2002.

[63] J. Li, Z. Zhao, J. Liu et al., "MEK/ERK and p38 MAPK regulate chondrogenesis of rat bone marrow mesenchymal stem cells through delicate interaction with TGF- $\beta 1 /$ Smads pathway," Cell Proliferation, vol. 43, no. 4, pp. 333-343, 2010.

[64] M. L. Burch, S. N. Y. Yang, M. L. Ballinger, R. Getachew, N. Osman, and P. J. Little, "TGF- $\beta$ stimulates biglycan synthesis via p38 and ERK phosphorylation of the linker region of Smad2," Cellular and Molecular Life Sciences, vol. 67, no. 12, pp. 2077-2090, 2010.

[65] R. Mao, Y. Fan, Y. Mou, H. Zhang, S. Fu, and J. Yang, "TAK1 lysine 158 is required for TGF- $\beta$-induced TRAF6-mediated Smad-independent IKK/NF- $\kappa$ B and JNK/AP-1 activation," Cellular Signalling, vol. 23, no. 1, pp. 222-227, 2011.

[66] M. Guma, D. Stepniak, H. Shaked et al., "Constitutive intestinal NF- $\kappa \mathrm{B}$ does not trigger destructive inflammation unless accompanied by MAPK activation," The Journal of Experimental Medicine, vol. 208, no. 9, pp. 1889-1900, 2011.

[67] S. Holland, O. Coste, D. D. Zhang, S. C. Pierre, G. Geisslinger, and K. Scholich, "The ubiquitin ligase MYCBP2 regulates transient receptor potential vanilloid receptor 1 (TRPV1) internalization through inhibition of p38 MAPK signaling," Journal of Biological Chemistry, vol. 286, no. 5, pp. 36713680, 2011.

[68] M. C. Lawrence, B. Naziruddin, M. F. Levy, A. Jackson, and K. McGlynn, "Calcineurin/nuclear factor of activated T cells and MAPK signaling induce TNF- $\alpha$ gene expression in pancreatic islet endocrine cells," Journal of Biological Chemistry, vol. 286, no. 2, pp. 1025-1036, 2011.

[69] M. E. Engel, M. A. McDonnell, B. K. Law, and H. L. Moses, "Interdependent SMAD and JNK signaling in transforming growth factor- $\beta$ - mediated transcription," Journal of Biological Chemistry, vol. 274, no. 52, pp. 37413-37420, 1999.

[70] L. Yu, M. C. Hébert, and Y. E. Zhang, "TGF- $\beta$ receptor-activated p38 MAP kinase mediates smad-independent TGF$\beta$ responses," EMBO Journal, vol. 21, no. 14, pp. 3749-3759, 2002.

[71] M. M. Martin, J. A. Buckenberger, J. Jiang et al., “TGF- $\beta 1$ stimulates human at 1 receptor expression in lung fibroblasts by cross talk between the Smad, p38 MAPK, JNK, and PI3K signaling pathways," American Journal of Physiology, vol. 293, no. 3, pp. L790-L799, 2007.

[72] K. M. Mulder and S. L. Morris, "Activation of p21(ras) by transforming growth factor $\beta$ in epithelial cells," Journal of Biological Chemistry, vol. 267, no. 8, pp. 5029-5031, 1992.

[73] A. Wong, B. Lamothe, A. Lee, J. Schlessinger, and I. Lax, "FRS2 $\alpha$ attenuates FGF receptor signaling by Grb2-mediated recruitment of the ubiquitin ligase Cbl," Proceedings of the National Academy of Sciences of the United States of America, vol. 99, no. 10, pp. 6684-6689, 2002.

[74] C. Reardon and D. M. McKay, "TGF- $\beta$ suppresses IFN- $\gamma$ STAT1-dependent gene transcription by enhancing STAT1PIAS1 interactions in epithelia but not monocytes/macrophages," Journal of Immunology, vol. 178, no. 7, pp. 42844295, 2007. 
[75] M. K. Lee, C. Pardoux, M. C. Hall et al., "TGF- $\beta$ activates Erk MAP kinase signalling through direct phosphorylation of ShcA," EMBO Journal, vol. 26, no. 17, pp. 3957-3967, 2007.

[76] J. Yue and K. M. Mulder, "Requirement of Ras/MAPK pathway activation by transforming growth factor $\beta$ for transforming growth factor $\beta 1$ production in a Smad-dependent pathway," Journal of Biological Chemistry, vol. 275, no. 40, pp. 30765-30773, 2000.

[77] K. Yamaguchi, K. Shirakabe, H. Shibuya et al., "Identification of a member of the MAPKKK family as a potential Mediator of TGF- $\beta$ signal transduction," Science, vol. 270 , no. 5244, pp. 2008-2011, 1995.

[78] M. Takekawa, K. Tatebayashi, F. Itoh, M. Adachi, K. Imai, and H. Saito, "Smad-dependent GADD $45 \beta$ expression mediates delayed activation of p38 MAP kinase by TGF- $\beta$," EMBO Journal, vol. 21, no. 23, pp. 6473-6482, 2002.

[79] P. G. Santamaria and A. R. Nebreda, "Deconstructing ERK signaling in tumorigenesis," Molecular Cell, vol. 38, no. 1, pp. $3-5,2010$.

[80] J. H. Zuo, W. Zhu, M. Y. Li et al., "Activation of EGFR promotes squamous carcinoma SCC10A cell migration and invasion via inducing EMT-like phenotype change and MMP-9-mediated degradation of E-cadherin," Journal of Cellular Biochemistry, vol. 112, no. 9, pp. 2508-2517, 2011.

[81] J. P. Thiery, "Cell adhesion in development: a complex signaling network," Current Opinion in Genetics and Development, vol. 13, no. 4, pp. 365-371, 2003.

[82] J. Zavadil, M. Bitzer, D. Liang et al., "Genetic programs of epithelial cell plasticity directed by transforming growth factor- $\beta$," Proceedings of the National Academy of Sciences of the United States of America, vol. 98, no. 12, pp. 6686-6691, 2001.

[83] M. Davies, M. Robinson, E. Smith, S. Huntley, S. Prime, and I. Paterson, "Induction of an epithelial to mesenchymal transition in human immortal and malignant keratinocytes by TGF- $\beta 1$ involves MAPK, Smad and AP- 1 signalling pathways," Journal of Cellular Biochemistry, vol. 95, no. 5, pp. 918-931, 2005.

[84] R. U. De Iongh, E. Wederell, F. J. Lovicu, and J. W. McAvoy, "Transforming growth factor- $\beta$-induced epithelial-mesenchymal transition in the lens: a model for cataract formation," Cells Tissues Organs, vol. 179, no. 1-2, pp. 43-55, 2005.

[85] J. Zavadil and E. P. Böttinger, "TGF- $\beta$ and epithelial-tomesenchymal transitions," Oncogene, vol. 24 , no. 37, pp. 5764-5774, 2005.

[86] L. Xie, B. K. Law, A. M. Chytil, K. A. Brown, M. E. Aakre, and H. L. Moses, "Activation of the Erk pathway is required for TGF- $\beta 1$-induced EMT in vitro," Neoplasia, vol. 6, no. 5, pp. 603-610, 2004.

[87] R. Strippoli, I. Benedicto, M. L. P. Lozano, A. Cerezo, M. López-Cabrera, and M. A. Del Pozo, "Epithelial-to-mesenchymal transition of peritoneal mesothelial cells is regulated by an ERK/NF- $\kappa \mathrm{B} /$ Snaill pathway," Disease Models and Mechanisms, vol. 1, no. 4-5, pp. 264-274, 2008.

[88] A. Cano, M. A. Pérez-Moreno, I. Rodrigo et al., "The transcription factor Snail controls epithelial-mesenchymal transitions by repressing E-cadherin expression," Nature Cell Bio$\log y$, vol. 2, no. 2, pp. 76-83, 2000.

[89] P. A. Pérez-Mancera, I. González-Herrero, M. Pérez-Caro et al., "SLUG in cancer development," Oncogene, vol. 24, no. 19, pp. 3073-3082, 2005.

[90] J. Choi, S. Y. Park, and C. K. Joo, "Transforming growth factor- $\beta 1$ represses E-cadherin production via Slug expression in lens epithelial cells," Investigative Ophthalmology and Visual Science, vol. 48, no. 6, pp. 2708-2718, 2007.
[91] K. Lehmann, E. Janda, C. E. Pierreux et al., "Raf induces TGF $\beta$ production while blocking its apoptotic but not invasive responses: a mechanism leading to increased malignancy in epithelial cells," Genes and Development, vol. 14, no. 20, pp. 2610-2622, 2000.

[92] L. Xie, B. K. Law, M. E. Aakre et al., "Transforming growth factor beta-regulated gene expression in a mouse mammary gland epithelial cell line," Breast Cancer Research, vol. 5, no. 6, pp. R187-R198, 2003.

[93] R. S. Frey and K. M. Mulder, "Involvement of extracellular signal-regulated kinase 2 and stress- activated protein kinase/ Jun $\mathrm{N}$-terminal kinase activation by transforming growth factor $\beta$ in the negative growth control of breast cancer cells," Cancer Research, vol. 57, no. 4, pp. 628-633, 1997.

[94] N. A. Bhowmick, R. Zent, M. Ghiassi, M. McDonnell, and H. L. Moses, "Integrin $\beta 1$ signaling is necessary for transforming growtn factor- $\beta$ activation of $\mathrm{p} 38 \mathrm{MAPK}$ and epithelial plasticity," Journal of Biological Chemistry, vol. 276, no. 50, pp. 46707-46713, 2001.

[95] J. H. Shim, C. Xiao, A. E. Paschal et al., "TAK1, but not TAB1 or TAB2, plays an essential role in multiple signaling pathways in vivo," Genes and Development, vol. 19, no. 22, pp. 2668-2681, 2005.

[96] R. Strippoli, I. Benedicto, M. Foronda et al., "p38 maintains E-cadherin expression by modulating TAK1-NF- $\kappa$ B during epithelial-to-mesenchymal transition," Journal of Cell Science, vol. 123, no. 24, pp. 4321-4331, 2010.

[97] A. Sorrentino, N. Thakur, S. Grimsby et al., "The type I TGF$\beta$ receptor engages TRAF6 to activate TAK1 in a receptor kinase-independent manner," Nature Cell Biology, vol. 10, no. 10, pp. 1199-1207, 2008.

[98] M. Yamashita, K. Fatyol, C. Jin, X. Wang, Z. Liu, and Y. E. Zhang, "TRAF6 mediates Smad-independent activation of JNK and p38 by TGF- $\beta$," Molecular Cell, vol. 31 , no. 6, pp. 918-924, 2008.

[99] A. V. Bakin, C. Rinehart, A. K. Tomlinson, and C. L. Arteaga, "p38 mitogen-activated protein kinase is required for TGF $\beta$ mediated fibroblastic transdifferentiation and cell migration," Journal of Cell Science, vol. 115, no. 15, pp. 3193-3206, 2002.

[100] I. E. Zohn, Y. Li, E. Y. Skolnik, K. V. Anderson, J. Han, and L. Niswander, "p38 and a p38-interacting protein are critical for downregulation of E-cadherin during mouse gastrulation," Cell, vol. 125, no. 5, pp. 957-969, 2006.

[101] Y. Liu, S. El-Naggar, D. S. Darling, Y. Higashi, and D. C. Dean, "Zeb1 links epithelial-mesenchymal transition and cellular senescence," Development, vol. 135, no. 3, pp. 579-588, 2008.

[102] J. C. Hedges, M. A. Dechert, I. A. Yamboliev et al., "A role for p38(MAPK)/HSP27 pathway in smooth muscle cell migration," Journal of Biological Chemistry, vol. 274, no. 34, pp. 24211-24219, 1999.

[103] S. Edlund, M. Landström, C. H. Heldin, and P. Aspenström, "Transforming growth factor- $\beta$-induced mobilization of actin cytoskeleton requires signaling by small GTPases Cdc42 and RhoA," Molecular Biology of the Cell, vol. 13, no. 3, pp. 902-914, 2002.

[104] B. R. Hu, C. L. Liu, and D. J. Park, "Alteration of MAP kinase pathways after transient forebrain ischemia," Journal of Cerebral Blood Flow and Metabolism, vol. 20, no. 7, pp. 1089-1095, 2000.

[105] Z. -M. Lv, Q. Wang, Q. Wan et al., “The role of the p38 MAPK signaling pathway in high glucose-induced epithelial-mesenchymal transition of cultured human renal tubular epithelial cells," PLoS One, vol. 6, no. 7, Article ID e22806, 2011. 
[106] M. Mariasegaram, G. H. Tesch, S. Verhardt, L. Hurst, H. Y. Lan, and D. J. Nikolic-Paterson, "Lefty antagonises TGF- $\beta 1$ induced epithelial-mesenchymal transition in tubular epithelial cells," Biochemical and Biophysical Research Communications, vol. 393, no. 4, pp. 855-859, 2010.

[107] B. Herrera, M. Fernández, C. Roncero et al., "Activation of p38MAPK by TGF- $\beta$ in fetal rat hepatocytes requires radical oxygen production, but is dispensable for cell death," FEBS Letters, vol. 499, no. 3, pp. 225-229, 2001.

[108] D. Y. Rhyu, Y. Yang, H. Ha et al., "Role of reactive oxygen species in TGF- $\beta 1$-induced mitogen-activated protein kinase activation and epithelial-mesenchymal transition in renal tubular epithelial cells," Journal of the American Society of Nephrology, vol. 16, no. 3, pp. 667-675, 2005.

[109] H. Wu, X. Wang, S. Liu et al., "Sema4C participates in myogenic differentiation in vivo and in vitro through the p38 MAPK pathway," European Journal of Cell Biology, vol. 86, no. 6, pp. 331-344, 2007.

[110] R. P. Kruger, J. Aurandt, and K. L. Guan, "Semaphorins command cells to move," Nature Reviews Molecular Cell Biology, vol. 6, no. 10, pp. 789-800, 2005.

[111] J. R. Basile, A. Barac, T. Zhu, K. L. Guan, and J. S. Gutkind, "Class IV semaphorins promote angiogenesis by stimulating Rho-initiated pathways through plexin-B," Cancer Research, vol. 64, no. 15, pp. 5212-5224, 2004.

[112] R. J. Pasterkamp, J. J. Peschon, M. K. Spriggs, and A. L. Kolodkin, "Semaphorin 7A promotes axon outgrowth through integrins and MAPKs," Nature, vol. 424, no. 6947, pp. 398405, 2003.

[113] K. Suzuki, A. Kumanogoh, and H. Kikutani, "Semaphorins and their receptors in immune cell interactions," Nature Immunology, vol. 9, no. 1, pp. 17-23, 2008.

[114] R. Zeng, M. Han, Y. Luo et al., "Role of Sema4C in TGF$\beta 1$-induced mitogen-activated protein kinase activation and epithelialmesenchymal transition in renal tubular epithelial cells," Nephrology Dialysis Transplantation, vol. 26, no. 4, pp. 1149-1156, 2011.

[115] P. Momeni, G. Glöckner, O. Schmidt et al., "Mutations in a new gene, encoding a zinc-finger protein, cause trichorhino-phalangeal syndrome type I," Nature Genetics, vol. 24, no. 1, pp. 71-74, 2000.

[116] Z. Gai, G. Zhou, S. Itoh et al., "Trps1 functions downstream of Bmp7 in kidney development," Journal of the American Society of Nephrology, vol. 20, no. 11, pp. 2403-2411, 2009.

[117] R. Derynck, R. J. Akhurst, and A. Balmain, “TGF- $\beta$ signaling in tumor suppression and cancer progression," Nature Genetics, vol. 29, no. 2, pp. 117-129, 2001.

[118] P. M. Siegel and J. Massagué, "Cytostatic and apoptotic actions of TGF- $\beta$ in homeostasis and cancer," Nature Reviews Cancer, vol. 3, no. 11, pp. 807-821, 2003.

[119] M. P. De Caestecker, E. Piek, and A. B. Roberts, "Role of transforming growth factor- $\beta$ signaling in cancer," Journal of the National Cancer Institute, vol. 92, no. 17, pp. 1388-1402, 2000.

[120] R. C. Bates and A. M. Mercurio, "Tumor necrosis factor- $\alpha$ stimulates the epithelial-tomesenchymal transition of human colonic organoids," Molecular Biology of the Cell, vol. 14, no. 5, pp. 1790-1800, 2003.

[121] R. J. Orton, O. E. Sturm, V. Vyshemirsky, M. Calder, D. R. Gilbert, and W. Kolch, "Computational modelling of the receptor-tyrosine-kinase-activated MAPK pathway," Biochemical Journal, vol. 392, no. 2, pp. 249-261, 2005. 

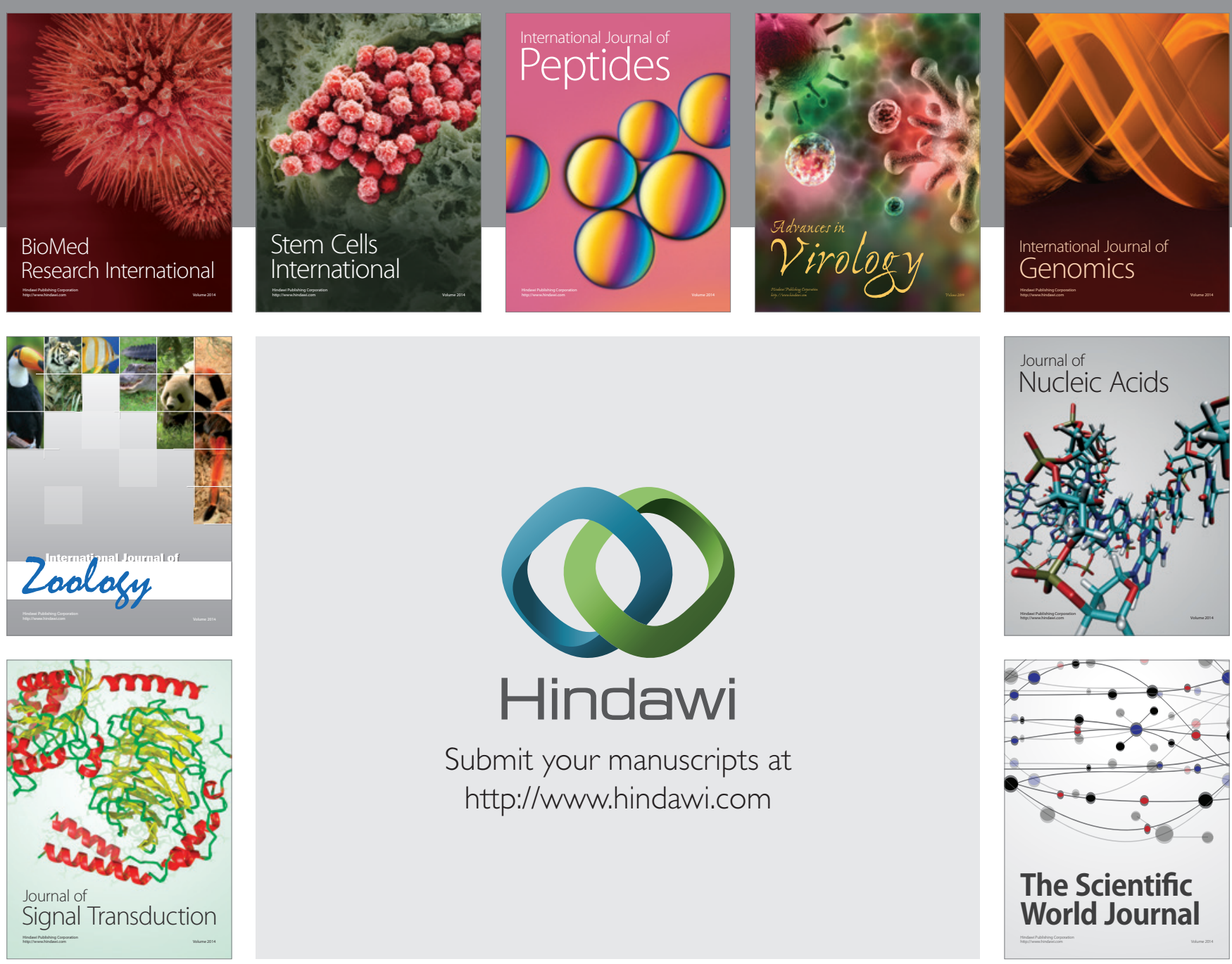

Submit your manuscripts at

http://www.hindawi.com
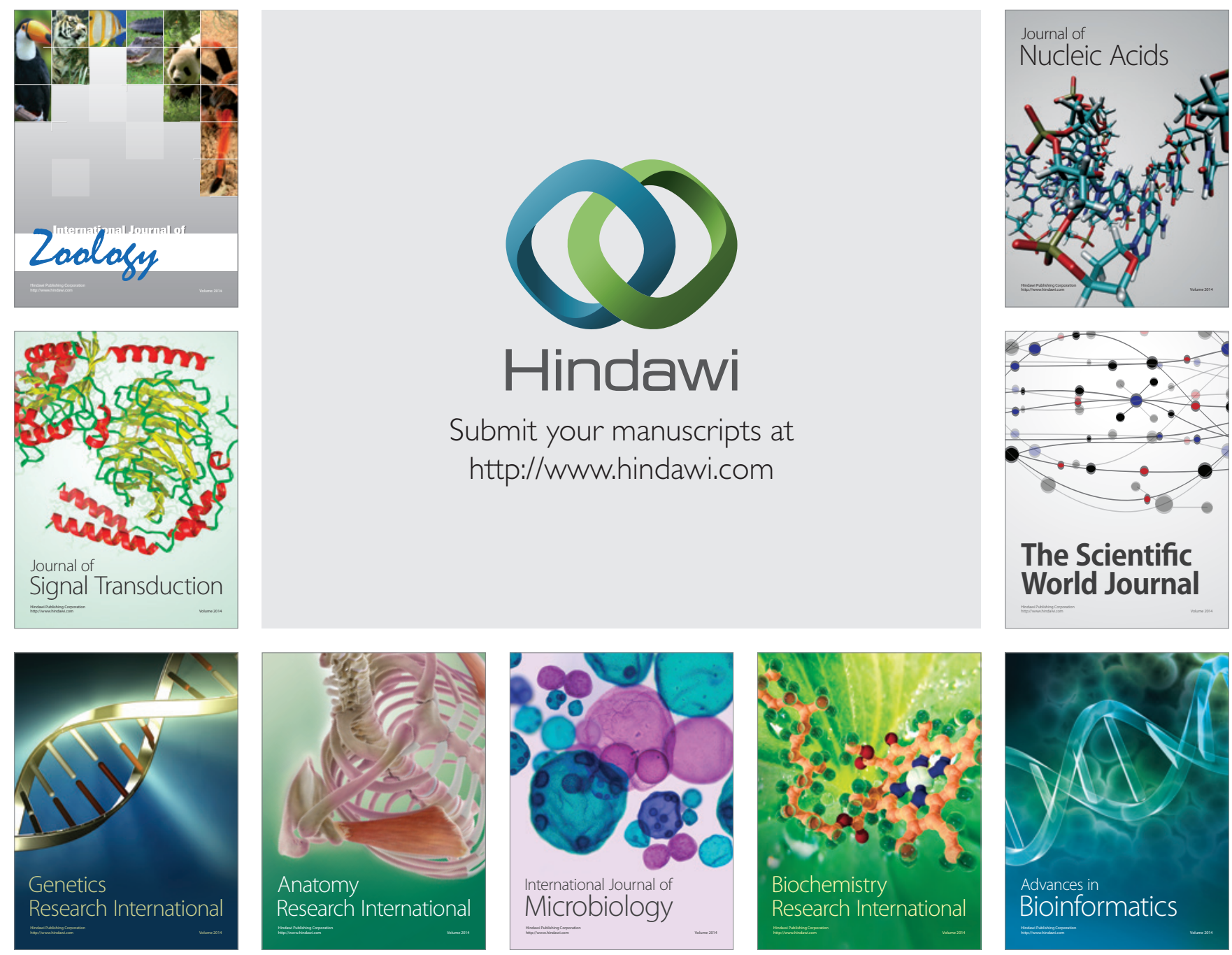

The Scientific World Journal
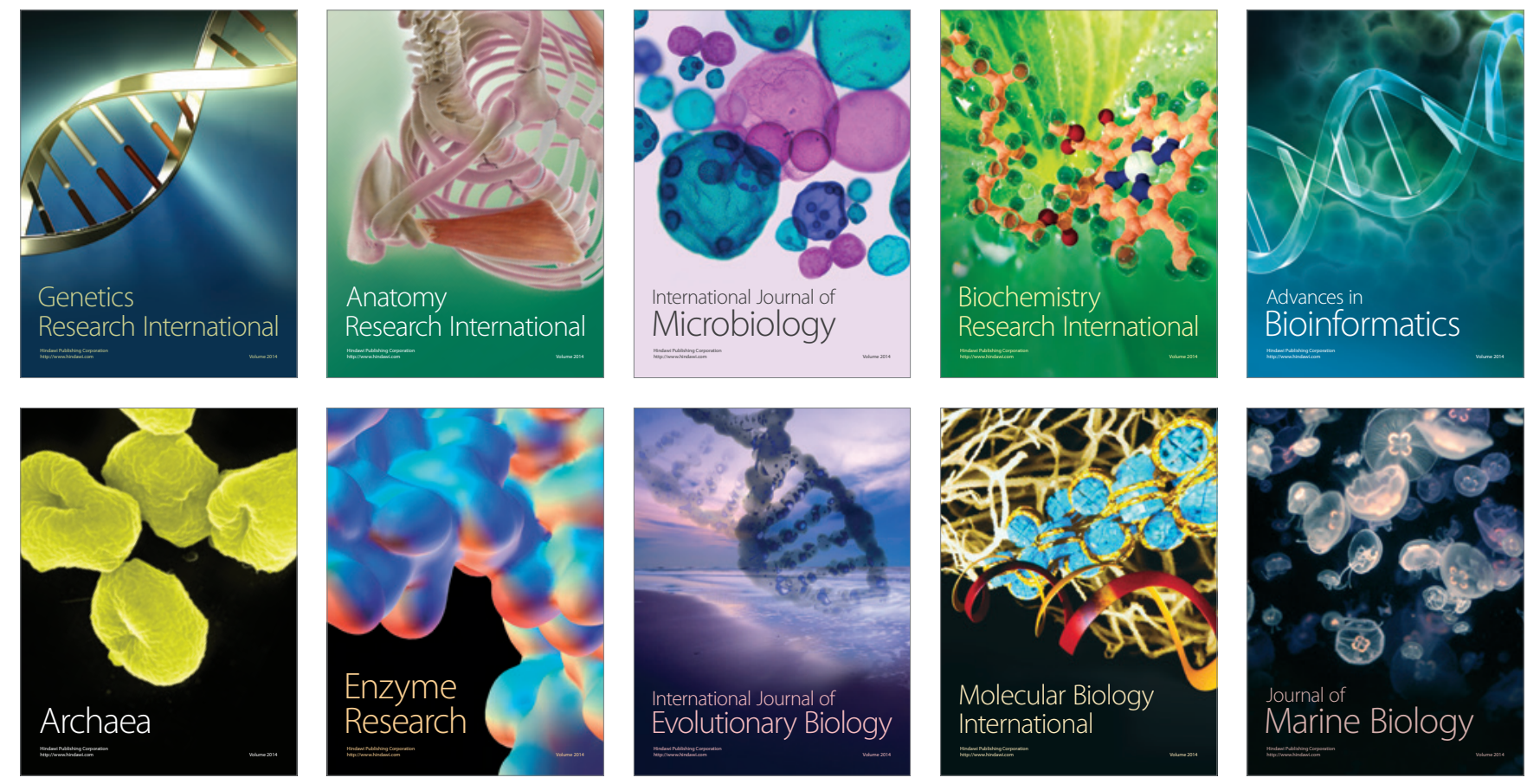